\title{
AVALIAÇÃO DA RECICLABILIDADE E DESMONTABILIDADE DE PRODUTOS ELETRÔNICOS UTILIZANDO A FERRAMENTA PARA DIAGNÓSTICO DA RECICLABILIDADE DE UM PRODUTO
}

\author{
Alexandre Augusto Karl (UFSC) alexandreaugustokarl@gmail.com \\ Lucila Maria de Souza Campos (UFSC) lucila.campos@ufsc.br
}

\begin{abstract}
Resumo
O pleno entendimento do conjunto de técnicas de reaproveitamento de materiais desde o design do produto, a fim de reintroduzi-los no ciclo produtivo, tem recebido maior notoriedade no âmbito organizacional. Dessa forma, o reconhecimento de índices de reciclabilidade e desmontabilidade de materiais se faz necessário como meio de garantir a conservação dos recursos naturais de maneira simplificada e sustentável. O presente estudo tem por escopo a aplicação da proposta de alteração do projeto de um produto ainda na fase de elaboração, utilizando-se a Ferramenta para Diagnóstico da Reciclabilidade de um Produto, baseada no mapeamento da Bill of Materials. Essa ferramenta é aplicada na desmontagem de um monitor LCD de 23 polegadas, queimado, de uso comum no mercado de informática, analisando-se todos os componentes do monitor em termos de índices apresentados na ferramenta. Como resultado, identificou-se a eficácia da ferramenta e o oferecimento de sugestões de alterações de componentes no projeto do monitor com a finalidade de melhorar sua desmontabilidade e reciclabilidade minimizando, assim, seus impactos negativos sobre o meio ambiente.
\end{abstract}

Palavras-chave: Reciclabilidade, Bill of Materials, Sustentabilidade. 


\section{Introdução}

A preocupação com os danos ao meio ambiente e a procura por produtos ambientalmente sustentáveis têm crescido exponencialmente nos últimos anos em função do aumento expressivo no consumo. Assim, fazem-se necessárias ações que realmente sejam efetivas na redução dos impactos ambientais causados especialmente na produção industrial que é o maior agente, potencialmente, poluidor na atualidade.

Pode-se notar, principalmente em países em desenvolvimento, que os setores industriais têm por preferência seguir uma abordagem de fim-de-tubo, a qual, caso comparada com um tratamento estratégico interno dos processos e produtos a fim de os tornar sustentáveis, impactando de forma negativa no meio ambiente (MOSTAFA; PETERS, 2017).

Cumpre salientar, que para o desenvolvimento de técnicas que auxiliam no desenvolvimento de produtos ambientalmente corretos é que surgiram conceitos como Administração da Qualidade Ambiental (TQEM), Produção mais Limpa, Ecoeficiência e Design for Enviroment (Ecodesign). Infere-se que o conceito utilizado como referência para a realização deste projeto, apesar de não estar explícito em estudos passados, enquadra-se principalmente na concepção de ecodesign, pelas alterações técnicas sustentáveis que podem ser aplicadas no projeto do produto.

Propor alterações no projeto com a finalidade de torná-lo sustentável e examinar todo o ciclo de vida de um produto são fatores cada vez mais relevantes, eis que, tais práticas minimizam os impactos ambientais em todas as fases, desde a fabricação até o descarte (GIANETTI; ALMEIDA, 2006). Em virtude do que foi mencionado, o problema conceitual é abordado com o objetivo inicial de desmontar o componente eletrônico e realizar a sua avaliação, utilizando-se a Ferramenta para Diagnóstico da Reciclabilidade de um Produto e aplicando a proposta de alteração do projeto de um produto ainda na fase de elaboração.

No tocante à responsabilidade global empresarial de garantir a sustentabilidade dos seus produtos em todo o seu ciclo de vida, destaca-se a importância do presente estudo em reduzir os impactos ambientais desde o projeto conceitual, os quais possuem diferentes ferramentas de tratamento e avaliação. Assim, a aplicação da ferramenta exposta serve como elemento norteador em soluções ecologicamente corretas em projetos de produtos, validando sua qualidade e aplicabilidade.

$\mathrm{O}$ artigo está dividido em quatro partes. A primeira apresenta os resultados conceituais obtidos, dissertando sobre desmontagem e reciclagem de produtos e a Ferramenta para 
Diagnóstico da Reciclabilidade de um Produto. Em seguida, a metodologia é exibida, com a fundamentação do projeto e os índices de reciclabilidade e desmontabilidade. A terceira parte aponta o resultado do processo de desmontagem e os resultados gráficos obtidos, além da análise final por componente. A última parte expõe as considerações finais do artigo.

\section{Referencial Teórico}

\subsection{Demontagem e Reciclagem de Produtos}

A reciclagem pode ser avaliada realizando uma análise de critérios atribuídos a cada estratégia de final de vida para um dado produto, quais sejam: regulamentação, custos, ganhos monetários, tecnologia e impacto ambiental. Por outro lado, pode-se também utilizar a capacidade de reciclagem dos materiais (DHOUIB; ELLOUMI, 2011).

A preservação dos recursos naturais, cada vez mais escassos, tornou-se primordial no objetivo de minimizar os impactos ambientais, tendo a reciclagem de materiais do final de vida como ponto-chave. Ainda, considera-se que o reaproveitamento dos materiais está atrelado à capacidade de determinado material ser reaproveitado, originando um novo componente ou produto (VEFAGO; AVELLANEDA, 2013).

Nesse sentido, pode-se então, segundo Kuo (2010), utilizar índices para mensurar o nível e capacidade de reciclabilidade de um material. $\mathrm{Na}$ avaliação de um produto tanto seus componentes precisam ser facilmente recicláveis, como também devem ser de alcance e desmontagem fáceis. Em outras palavras, nada adianta o produto ter um componente de um material que pode ser reciclado se não há acessibilidade para desmontagem de determinada peça.

De acordo com Kuo (2006), a separação de um produto em vários componentes é caracterizada como desmontagem, sendo um processo para tornar economicamente viável a reciclagem. Ainda, Yu et al. (2011) apresentam que o fator econômico é determinante na desmontagem de produtos, visto que as peças desmontadas adquirem valor líquido maior, caso comparadas com a comercialização do produto como um todo.

Em suma, parâmetros como o grau de precisão para alocar corretamenta a ferramenta, peso e tamanho do produto em questão, formato dos componentes desmontados, material e uso de ferramentas automáticas ou manuais são partes do processo em questão, determinando a qualidade do projeto em relação à demontagem. 


\subsection{Ferramenta para Diagnóstico da Reciclabilidade de um Produto}

Ao se realizar um projeto de um produto, o projetista deve levar em consideração diversos fatores para a sua realização, fazendo uso da visão holística de todos os processos produtivos relacionados, além de seu ciclo de vida, principalmente quando o foco está em sua reciclabilidade (AGUIAR et al. 2014).

Vale também destacar, que a desmontagem das peças de um produto e a sua reciclagem são os dois fatores principais na análise do projeto de um produto eco-sustentável. Por conta disso, variáveis como a facilidade de separação dos componentes de um produto, assim como os materiais que o compõe são amplamente discutidos e analisados, com vistas à minimização dos impactos ambientais ao longo do ciclo de vida (KUO, 2010).

Segundo Olsen, Saetre e Thorstenson (1997), a separação da lista de todos os componentes de um determinado produto, com a sua denominação e quantidade são parte da criação da Bill of Materiais (BOM). Quando se trata de reciclabilidade de um produto, a BOM atua de maneira direta como meio de avaliar as peças em suas funções e características.

$\mathrm{Na}$ ferramenta em estudo, Aguiar et al. (2014) apontam que, incorporado à BOM, estão os índices de demontabilidade e reciclabilidade do produto, adquiridos por intermédio da análise da literatura e selecionados de acordo com a sua relevância para formação. À propósito, verifica-se que os índices apresentam menores valores quando estão cerca do estado ideal; maiores, reproduzem e refletem a necessidade imediata de redesign.

\section{Metodologia}

\subsection{Fundamentação do Projeto}

A ferramenta para diagnóstico da reciclabilidade de um produto, aplicada no presente estudo, é uma tentativa de preencher a lacuna existente a respeito de metodologias aplicadas a um produto para avaliar suas características em relação à reciclagem e possibilitar o seu aperfeiçoamento na fase de desenvolvimento do produto.

A ferramenta está baseada no conceito da Bill of Materials ( BOM), que é uma lista detalhada com as informações disponíveis sobre todas as peças usadas na produção de um item. A listagem deve trazer dados sobre componentes, sub-componentes, partes, materiais brutos, assim como sua quantidade e a relação que possuem entre si. 
A Lista de Materiais pode ser usada para fins diversos, como engenharia de produto, precificação, compras, manutenção, entre outros. Além disso, a ferramenta também pode ser aproveitada por empresas parceiras no desenvolvimento de um produto, servindo como um importante canal para troca e controle de informações.

Houve a tentativa de se conseguir outro monitor de LCD para fornecer dados comparativos entre dois monitores, todavia, pode-se obter apenas um monitor de tubo, na Prefeitura do Campus da Universidade Estadual de Santa Catarina (UDESC), o qual foi descartado com vistas na não disposição de ferramentas e formação técnica para desmontá-lo, além dos riscos provenientes da emissão de gases tóxicos.

\section{2 Índices de Desmontabilidade e Reciclabilidade}

A metodologia de avaliação do projeto do produto leva em consideração dois aspectos que são relativos à facilidade de desmontagem e à viabilidade de reciclagem. Para isso, desenvolveram-se índices para quantificar esses dois aspectos e se chegar a um dado numérico que oriente a formulação de ações corretivas.

\subsection{1 Índices referentes à desmontagem}

Conforme Giudice e Kassem (2009), uma das condicionantes que facilitam ou dificultam a desmontagem é o tempo gasto pra se retirar uma peça, com o uso de uma ou mais ferramentas. Assim, é bastante relevante minimizar o tempo gasto na desmontagem utilizando-se elementos de fixação mais padronizados e que demandem o menor número possível de ferramentas.

O trabalho de referência estabeleceu, na tabela 1 , o índice referente ao número de tipos de elementos de fixação, variando de 1 a 4 (sendo o 1 a melhor situação e o 4 a pior):

Tabela 1- Índice do número de elementos de fixação (INT
\begin{tabular}{|l|l|}
\hline Índice & Número de tipos de EF (INTEF) \\
\hline 1 & 1 tipo \\
\hline 2 & 2 tipos \\
\hline 3 & 3 tipos \\
\hline 4 & 4 ou mais tipos \\
\hline
\end{tabular}
Fonte: Aguiar et al. (2014)


Para Oliveira et al. (2013), este índice é referente à maneira como o elemento de fixação está atuando. Pode assumir valores que de 0 a 4 conforme a dificuldade para se retirá-lo, representando o valor 4 o maior grau de dificuldade.

\begin{tabular}{l} 
Tabela 2 - Índice do elemento de fixação (IEF) \\
\begin{tabular}{|l|l|}
\hline Índice & Elemento de Fixação (IEF) \\
\hline 0,80 & Click \\
\hline 1,10 & Fita Adesiva \\
\hline 1,10 & Trava \\
\hline 1,30 & Fixação Magnética \\
\hline 1,30 & Anel \\
\hline 1,60 & Velcro \\
\hline 1,60 & Parafuso \\
\hline 1,60 & Parafuso com porca \\
\hline 1,60 & Pino \\
\hline 1,90 & Arame \\
\hline 1,90 & Abraçadeira de Plástico \\
\hline 2,70 & Prego \\
\hline 2,90 & Cola \\
\hline 4,00 & Rebite \\
\hline
\end{tabular} Fonte: Oliveira et al. (2013) \\
\hline
\end{tabular}

De acordo com Kroll e Carver (1999) o que pode garantir melhor otimização do tempo na hora da desmontagem é a acessibilidade, sendo essa a medida da facilidade com que uma parte pode ser alcançada com a mão ou por uma ferramenta.

Tabela 3 - Índice de Acessibilidade (IA)

\begin{tabular}{|l|l|}
\hline Índice & Acessibilidade (IA) \\
\hline 1 & Livre \\
\hline 2 & Até $50 \%$ acessível \\
\hline 3 & Acima de 50\% inacessível \\
\hline 4 & Inacessível \\
\hline
\end{tabular}

Fonte: Aguiar et al. (2014)

\subsection{2 Índices referentes à reciclabilidade}

Este índice está relacionado com a logística reversa que a empresa proporciona com a finalidade de reciclar o produto no fim da sua vida. $O$ índice varia de 1 a 4 onde 1 representa a existência de uma infraestrutura local e o 4 a inexistência. 
Tabela 4 - Índice de Infraestrutura - IIF

\begin{tabular}{|l|l|}
\hline Índice & Infraestrutura (IIF) \\
\hline 1 & Local / Regional \\
\hline 2 & Nacional \\
\hline 3 & Internacional \\
\hline 4 & Inexistente / Desconhecido \\
\hline
\end{tabular}

Fonte: Aguiar et al. (2014)

A compatibilidade entre os materiais que compõem a peças é fundamental pra determinar o grau de dificuldade para a realização da reciclagem. O índice varia de 1 a 4, significando o 1 o melhor para a reciclagem.

Tabela 5 - Índice de compatibilidade de Materiais (ICDM)

\begin{tabular}{|l|l|}
\hline Índice & Compatibilidade de Materiais (ICDM) \\
\hline 1 & Mesmo material \\
\hline 2 & Materiais compatíveis \\
\hline 3 & Materiais pouco compatíveis \\
\hline 4 & Materiais não compatíveis \\
\hline
\end{tabular}

O índice é baseado na NBR 10.004 e indica o nível de periculosidade que pode haver em uma peça. Dependendo desta característica o custo da reciclagem poderá ser alto ou até mesmo inviabilizá-la.

Segundo a NBR 10.004 os resíduos inertes e não perigosos são aqueles que, quando amostrados de uma forma representativa, segundo a ABNT NBR 10007, e submetidos a um contato dinâmico e estático com água destilada ou desionizada, à temperatura ambiente, conforme ABNT NBR 10006, não tiverem nenhum de seus constituintes solubilizados a concentrações superiores aos padrões de potabilidade de água, excetuando-se aspecto de, cor, turbidez, dureza e sabor.

Os resíduos não inertes e não perigosos podem ter propriedades, tais como: biodegradabilidade, combustibilidade ou solubilidade em água. Os resíduos perigosos podem ter características de inflamabilidade, corrosividade, reatividade, toxicidade e patogenicidade. Os produtos de uso restrito são aqueles controlados pelo Exército, Polícia Federal, e outros órgãos governamentais e que pela sua natureza são usados em produtos muito específicos.

Tabele 6 - Índice de classificação do material (ICM)

\begin{tabular}{|c|l|}
\hline Índice & Classificação do material (ICM) \\
\hline 1 & Materiais Inertes e Não Perigosos \\
\hline
\end{tabular}




\begin{tabular}{|l|l|}
\hline 2 & Materiais Não Inertes e Não Perigosos \\
\hline 3 & Materiais Perigosos \\
\hline 4 & Material de Uso Restrito \\
\hline
\end{tabular}

Fonte: Aguiar et al. (2014)

A contaminação pode ocorrer devido à interferência da pintura, colagem e soldagem da peça durante o processo de fabricação. Este tipo de contaminação causará a inutilização da peça e a consequente perda da reciclabilidade.

Tabela 7 - Índice de Contaminação no Final de Vida - ICFV
\begin{tabular}{|c|c|}
\hline Índice & Contaminação Final de Vida (ICFV) \\
\hline 1 & Não contaminado \\
\hline 2 & Contaminado \\
\hline
\end{tabular}
Fonte: Aguiar et al. (2014)

Em suma, o presente estudo constitui, em prática, a ferramenta de análise supracitada em um caso concreto, ou seja, desmontando um aparelho eletrônico inservível.

\section{Resultados e Discussões}

\subsection{Processo de desmontagem e resultados gráficos obtidos}

Pôde-se realizar a desmontagem com uma duração de três horas e meia, na qual foi feito o levantamento fotográfico e o etiquetamento das peças. Concomitante ao levantamento fotográfico, foi-se realizada a classificação de cada peça de acordo com os índices das sete tabelas expostas na metodologia utilizada. A seguir, plotaram-se os índices em gráficos e por tabela, com todas as peças. Em seguida, pode-se evidenciar os gráficos das tabelas que avaliam a desmontagem. 
Figura 1 - Número de tipos de Elementos de Fixação

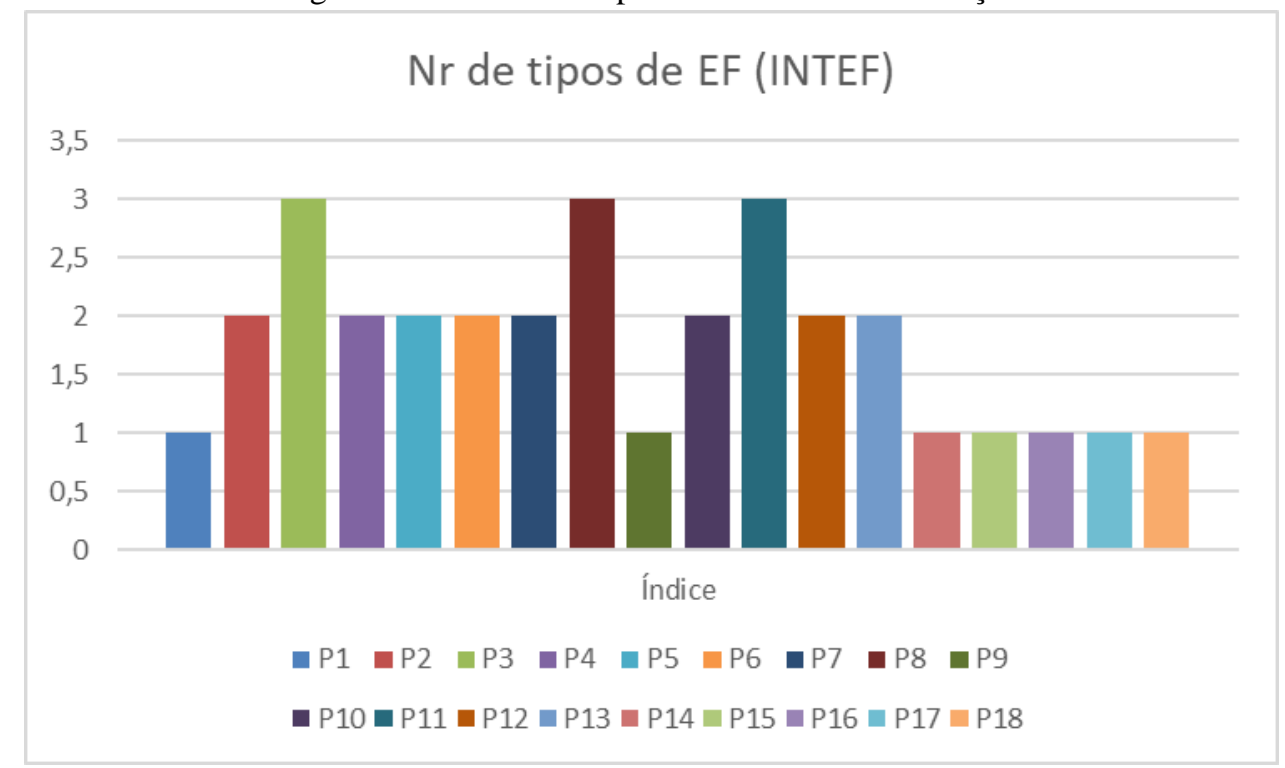

Fonte: Os autores (2020)

As peças 3, 8 e 11 apresentaram o maior número de tipos de elementos de fixação com 3 tipos.

Figura 2 -Índices do Elemento de Fixação

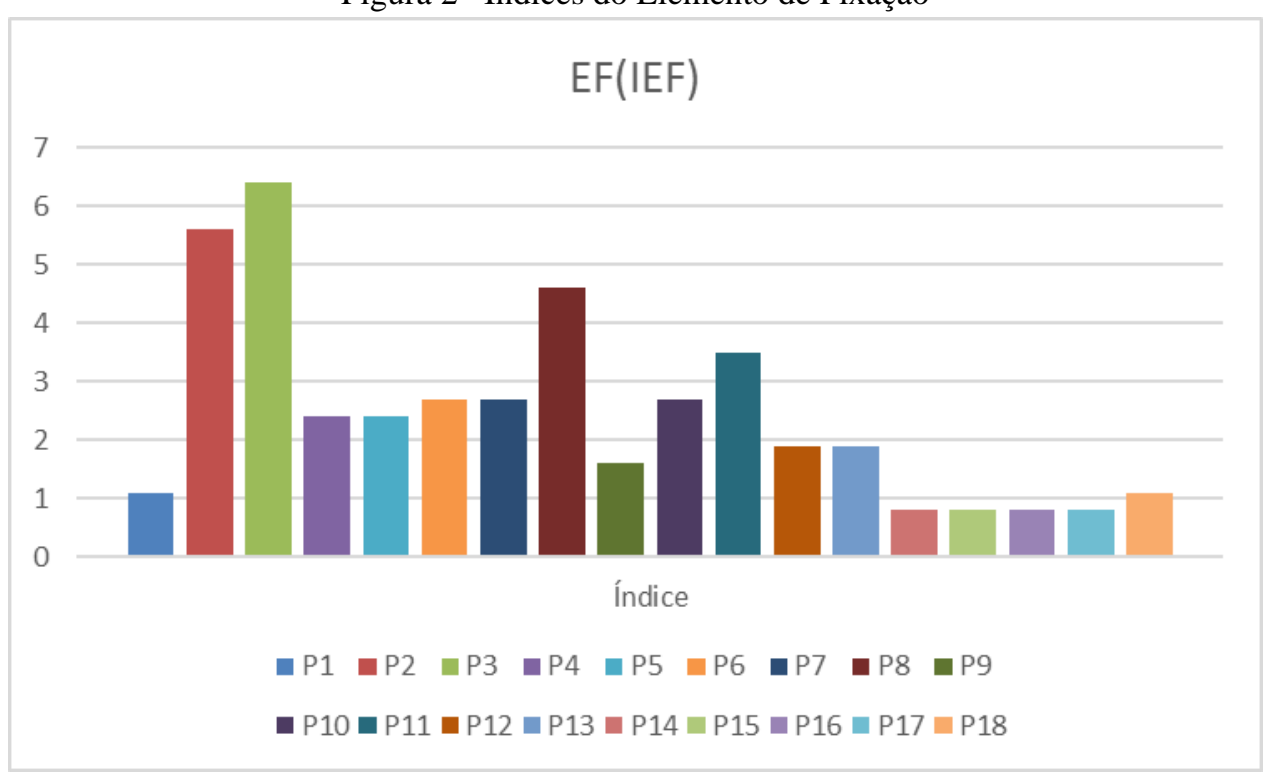

Fonte: Os autores (2020)

A peça 3 possui o maior número em índices de elementos de fixação, seguida pelas peças 2 e após a peça 8 . 
Figura 3 - Índice de Acessibilidade

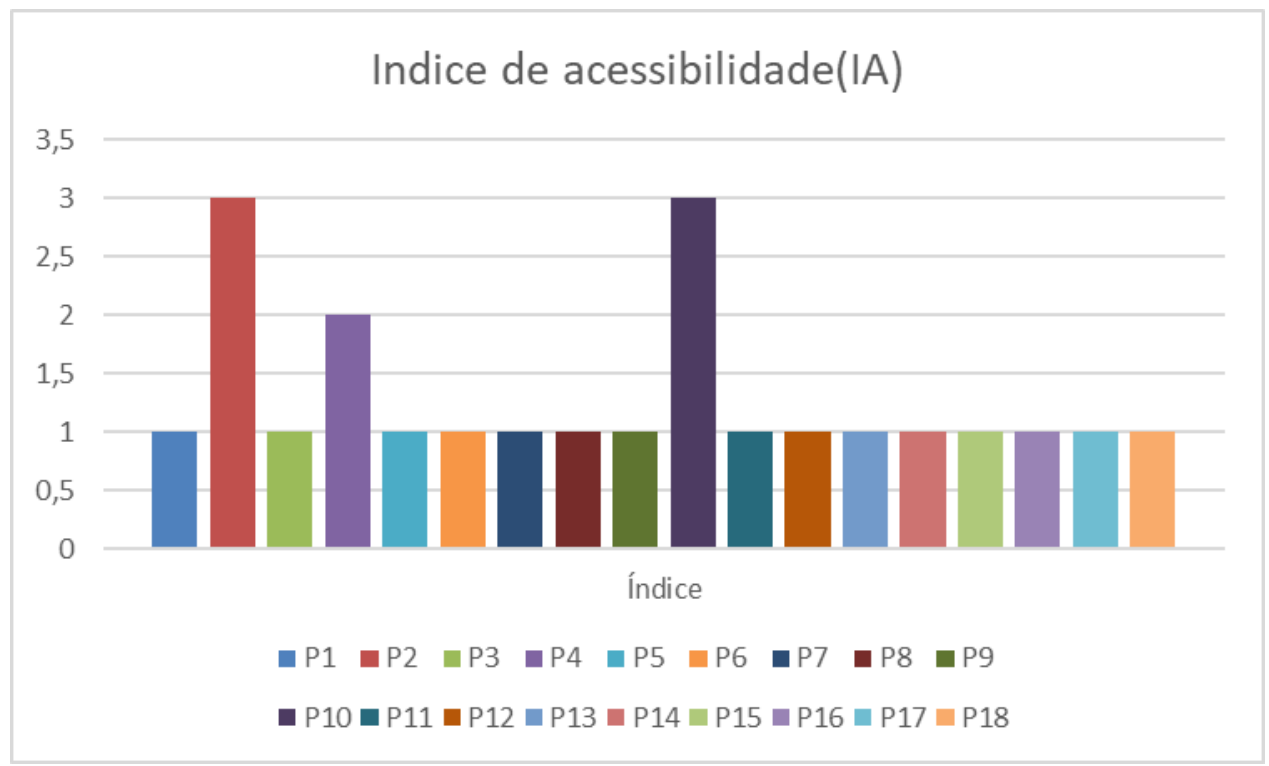

Fonte: Os autores (2020)

As peças 2 e 10 têm o maior índice de acessibilidade dos componentes analisados, ou seja, mais de $50 \%$ é inacessível, seguidas pela peça número 4, que até $50 \%$ é acessível. A seguir, pode-se apresentar os gráficos que avaliam a reciclabilidade dos componentes do televisor.

Figura 4 - Índice de Infraestrutura

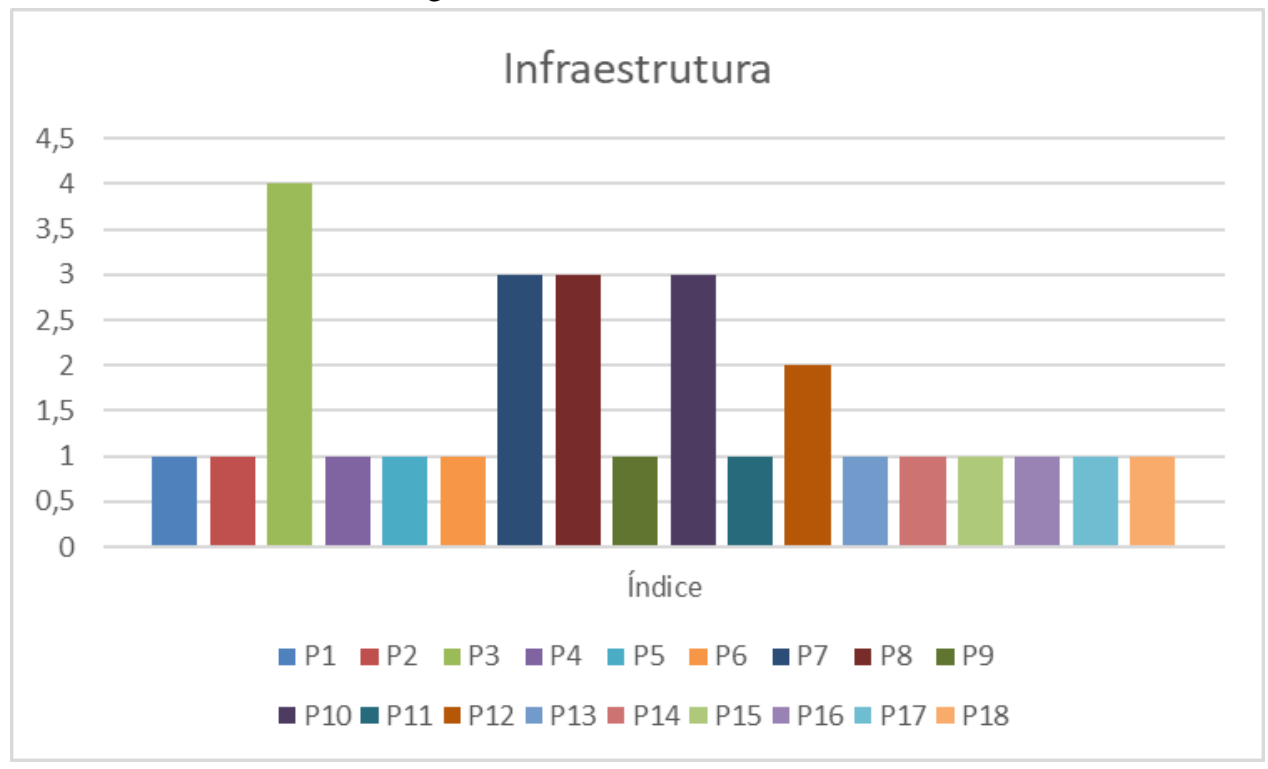

Fonte: Os autores (2020)

A peça 3 tem infraestrutura inexistente, em caso da necessidade de logística reversa. Enquanto isso, as peças 7, 8 e 10 possuem infraestrutura internacional, sendo que as demais ou são nacionais ou regionais. 
Figura 5 - Índice de compatibilidade de materiais

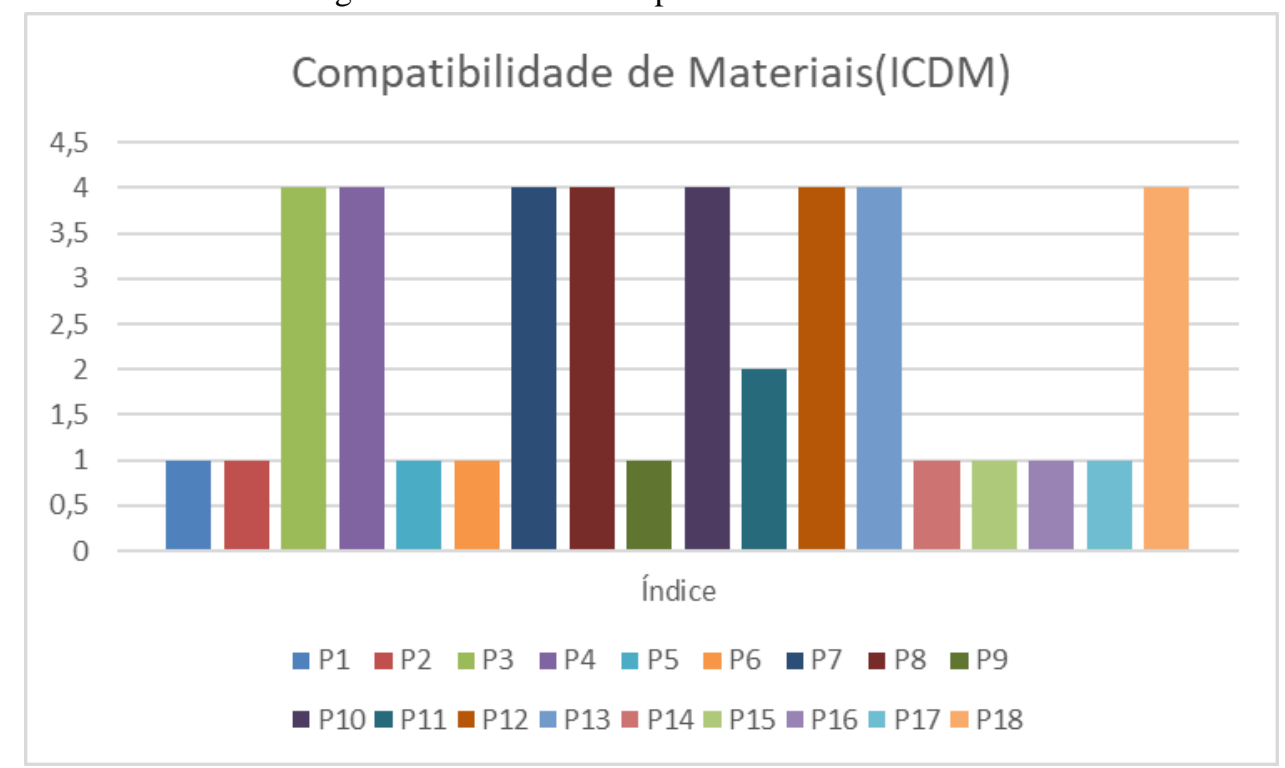

Fonte: Os autores (2020)

As peças de número 3, 4, 7, 8, 10, 12, 13 e 18 possuem elevado índice de compatibilidade, ou seja, são materiais incompatíveis e difíceis de reciclar. Os demais componentes apresentaram índice baixo, significando facilidade de reciclagem dos itens.

Figura 6 - Índice de Classificação do Material

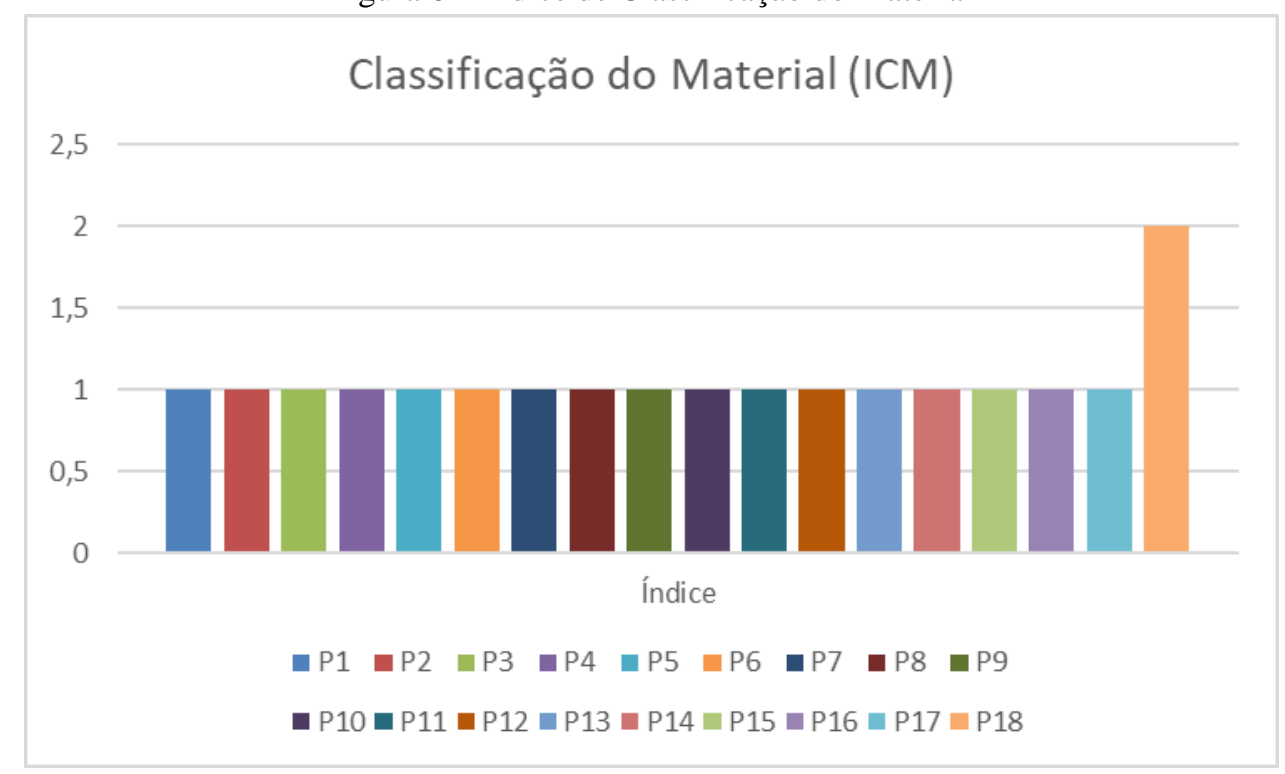

Fonte: Os autores (2020)

Apenas a peça 18 mostra alta classificação do material, mas por ter nível dois é denominado material não inerte e não perigoso. De mesmo modo, os outros itens, por possuírem nível um, são intertes e não perigosos. 
Figura 7 - Índice de contaminação de final de vida

\section{Contamin Final de Vida(ICFV)}

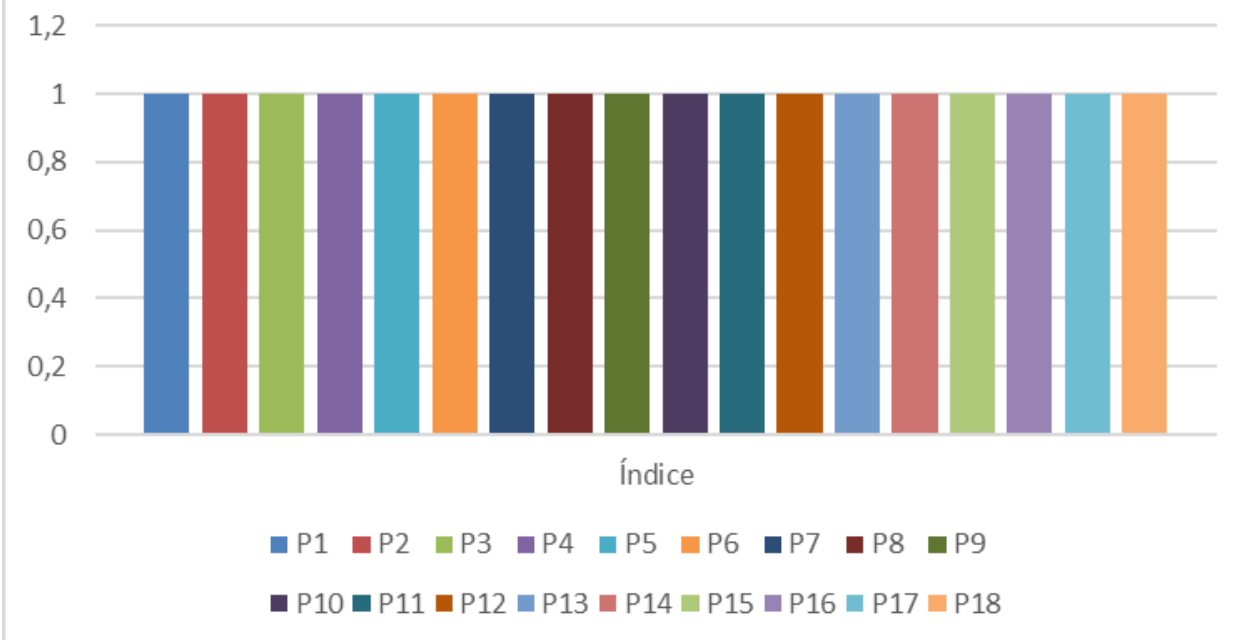

Fonte: Os autores (2020)

Todos os itens analisados apresentaram o mesmo índice na contaminação no final de vida, ou seja, não contaminado. Pôde-se apresentar, nas figuras 8 e 9, a soma por peça dos índices de desmontagem e reciclabilidade, respectivamente. Por decisão, optou-se por apresentar os valores numéricos, ao contrário do artigo que apresenta um degradê de cores variando do branco ao cinza, por ser de fácil visualização.

Figura 8 - Somatório de todos os índices referentes à desmontagem por peça

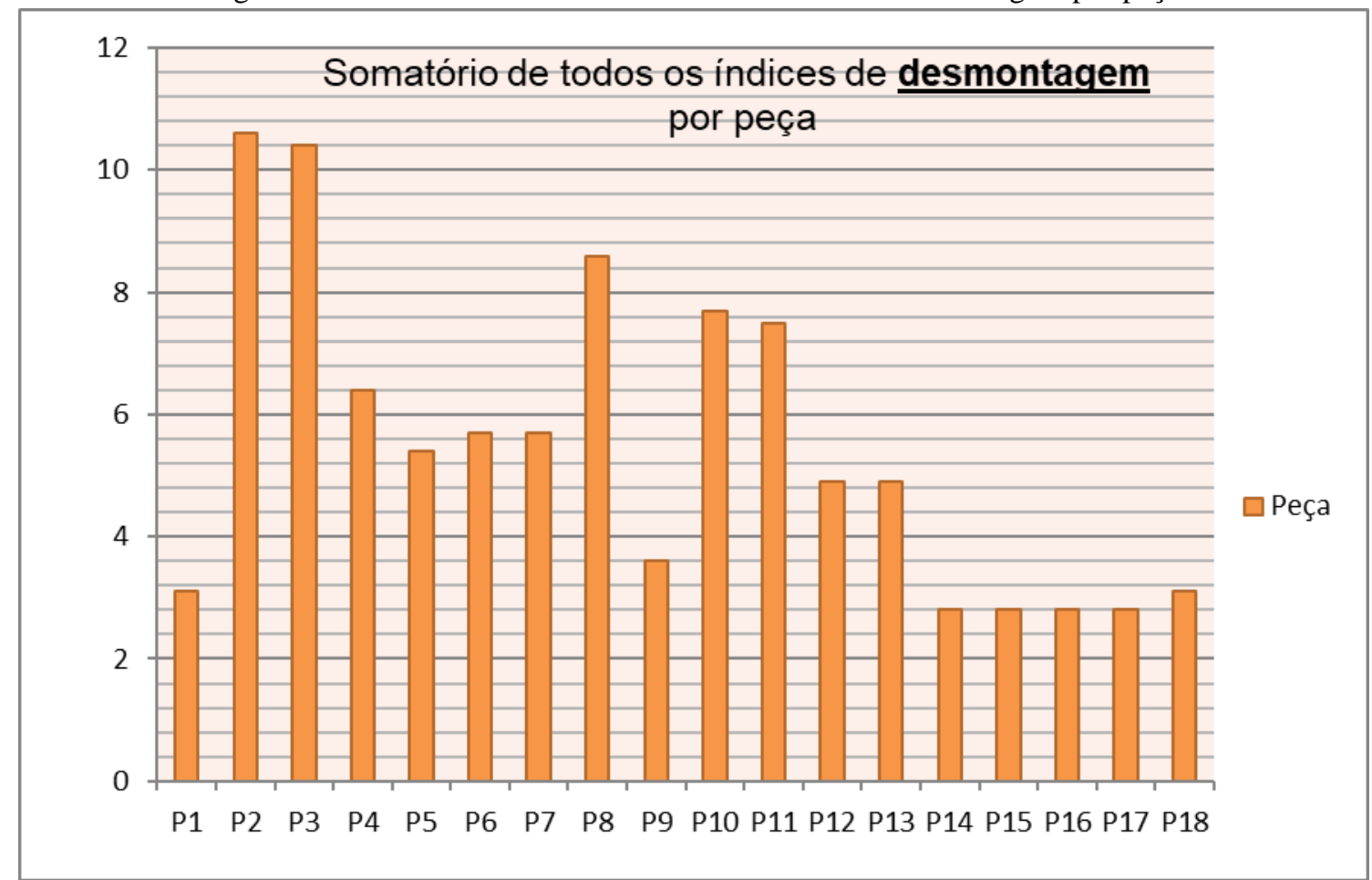

Fonte: Os autores (2020) 
Figura 9 - Somatório de todos os índices referentes à reciclabilidade por peça

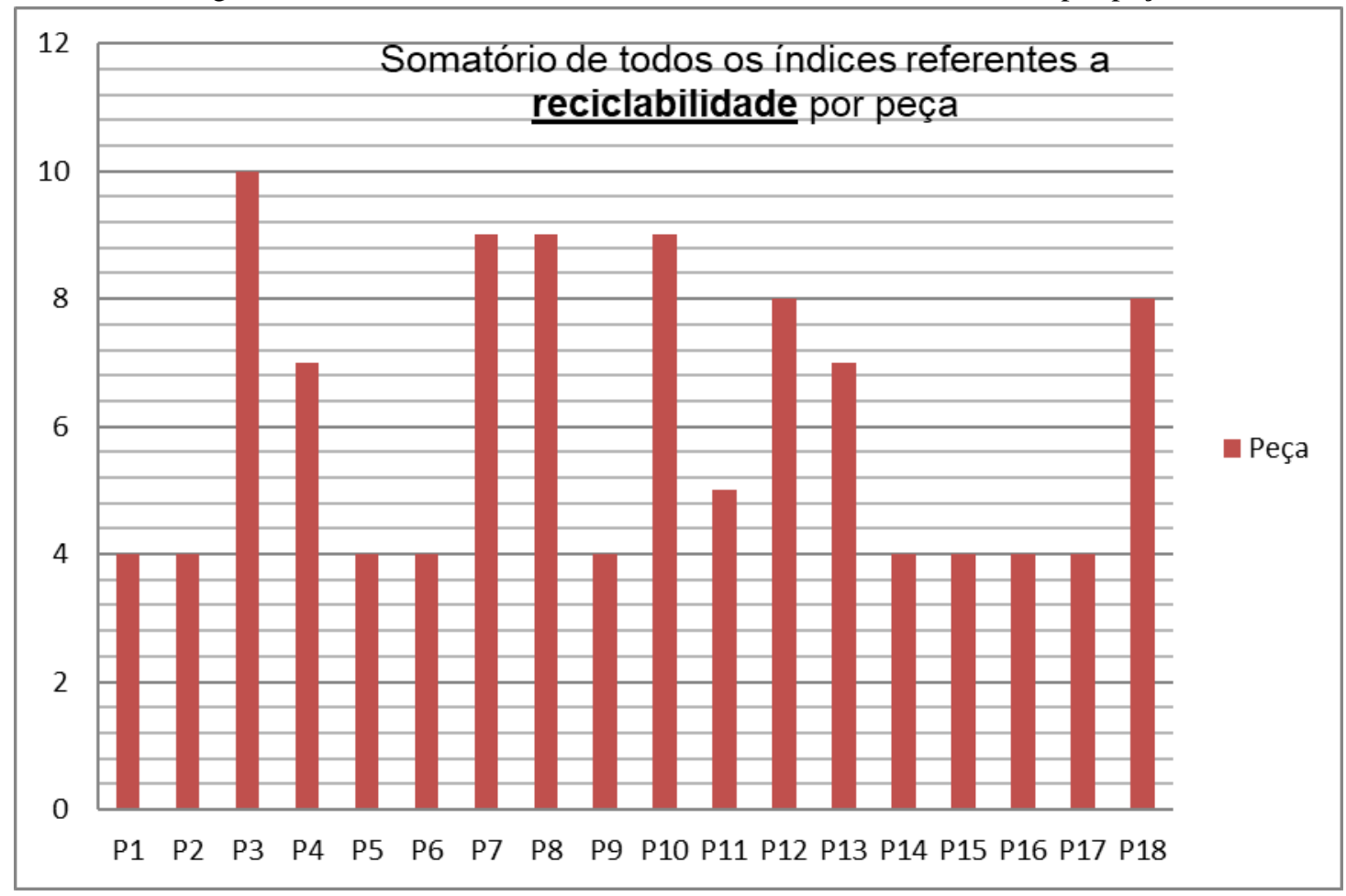

Fonte: Os autores (2020)

\subsection{Análise final por componente}

A seguir, o presente projeto de estudo encontra-se na sua fase de análises finais dos dados obtidos, destacando alguns componentes que podem ser reestruturados em termos de projeto de produto, com a finalidade de torná-los ecologicamente corretos. Pode-se observar que os componentes na sua grande maioria podem ser definidos como termoplásticos ABS, alumínio, aço inoxidável e placas CI livre de chumbo. Ainda, possuem resíduos não perigosos as peças $1,2,4,5$ e 6 , por conterem plástico e metal ferroso e resíduos perigosos as peças 3,7 e 8 , dado os circuitos eletrônicos encontrados.

\subsubsection{Base do monitor (peça 1)}

Por possuir um elemento de fixação (trava), índice de acessibilidade livre, infraestrutura local/ regional, Compatibilidade de Materiais (ICDM) nível 1 (mesmo material), Classificação do Material (ICM) como materiais inertes e não perigosos, Índice de Contaminação no Final de Vida (ICFV) como não contaminado; essa peça apresentou os melhores índices possíveis, então não necessita de uma reformulação em seu projeto. 


\subsubsection{Bloco Interno (peça 6)}

Com dois elementos de fixação (fita adesiva e parafuso), índice de acessibilidade livre, infraestrutura local/ regional, Compatibilidade de Materiais (ICDM) de nível um (mesmo material), Classificação do Material (ICM) como materiais inertes e não perigosos, Índice de Contaminação no Final de Vida (ICFV) como não contaminado; pode-se concluir que buscar uma maneira de utilizar apenas um elemento de fixação seria ecologicamente correto e viável, visto que, possivelmente apenas os parafusos já seriam capazes de cumprir o papel adequadamente.

\subsubsection{Placa metálica LCD (Peça 11)}

Possui três elementos de fixação (trava e parafusos), índice de acessibilidade livre, infraestrutura local/ regional, Compatibilidade de Materiais (ICDM) de nível dois (materiais compatíveis), Classificação do Material (ICM) como materiais inertes e não perigosos, Índice de Contaminação no Final de Vida (ICFV) como não contaminado; observa-se a possibilidade de buscar soluções para diminuir o número de elementos de fixação, dado a não necessidade de serem necessários 3 tipos diferentes.

\subsubsection{Plástico Branco (Peça 17)}

Com um elemento de fixação (click), índice de acessibilidade livre, infraestrutura local/ regional, Compatibilidade de Materiais (ICDM) nível um (mesmo material), Classificação do Material (ICM) como materiais inertes e não perigosos, Índice de Contaminação no Final de Vida (ICFV) como não contaminado; essa peça apresentou os melhores índices possíveis, então não necessita de uma reformulação em seu projeto.

\subsubsection{Moldura do LCD (Peça 2)}

Exibe dois elementos de fixação (trava e plug da placa de circuito frontal), índice de acessibilidade pouco acessível, infraestrutura local/ regional, Compatibilidade de Materiais (ICDM) nível um (mesmo material), Classificação do Material (ICM) como material não perigoso e inerte, Índice de Contaminação no Final de Vida (ICFV) como não contaminado; aponta-se que o projeto dessa peça quanto a acessibilidade deve ser revisto, pois para retirá-la requer demasiado uso de força. 


\subsubsection{Placa de circuito Impresso (Peça 7)}

Evidencia em sua estrutura dois elementos de fixação (parafuso e plug de outra placa de circuito impresso), índice de acessibilidade livre, infraestrutura internacional, Compatibilidade de materiais (ICDM) com materiais não compatíveis, Classificação do Material (ICM) como perigoso e Índice de Contaminação no Final de Vida como contaminado; observou-se que a reciclagem da placa de circuito impresso no Brasil ainda carece de investimento em pesquisa para desenvolver métodos de reciclagem que sejam baratos e não apresentem toxicidade.

\subsubsection{Vidro do LCD (Peça 12)}

Identificara-se dois elementos de fixação (duas travas diferentes), índice de acessibilidade livre, infraestrutura local/ regional, Compatibilidade de materiais (ICDM) com materiais não compatíveis, Classificação do Material (ICM) como não perigoso e inerte, Índice de Contaminação Final de Vida como não contaminado; fora constatado pelos bons índices apresentados que nada deve ser alterado no projeto dessa peça.

\subsubsection{Plástico Branco (Peça 17)}

Oferece um elemento de fixação (click), índice de acessibilidade livre, infraestrutura local/ regional, Compatibilidade de materiais (ICDM) com materiais não compatíveis, Classificação do Material (ICM) como não perigoso e inerte, Índice de Contaminação Final de Vida como não contaminado; por expor bons índices no presente estudo, o item analisado não tem necessidade de passar por uma reengenharia.

\section{Considerações Finais}

No contexto atual, grandes sociedades de consumo se sustentam na produção em massa de artigos de consumo, com o desejo à obtenção do excedente, - estrutura baseada na insatisfação do possuir o essencial - a qual, perante as constatações aduzidas, faz-se necessário adaptação para sobrevivência de mercado, levando em consideração o modus operandi produtivo e o cotidiano hodierno das pessoas. 
Nesse contexto, a adaptação mercadológica dos grandes fabricantes deve se basear no entendimento do avanço da produção intelectual sobre alternativas sustentáveis para os novos projetos de produtos. De mesmo modo, o estudo é importante para traçar estratégias verdes, com a finalidade de garantir produtos eco-sustentáveis. Logo, o artigo cumpriu com seu objetivo de aplicar a proposta de alteração do projeto de um produto ainda na fase de elaboração, utilizando-se a Ferramenta para Diagnóstico da Reciclabilidade de um Produto, baseada no mapeamento da Bill of Materials, ao analisar em um caso real características de reciclabilidade e desmontabilidade dos componentes de um televisor LCD.

O estudo tem por limitação a quantidade de itens analisados, visto que apenas um televisor LCD foi utilizado, não criando parâmetros de saturação de dados para diagnósticos de contraste entre os dados. Estudos futuros irão ampliar os itens e componentes observados, de modo a fundamentar os novos resultados provenientes dos novos entrantes. Além disso, como pesquisas futuras sugere-se o estudo e reconhecimento de outras metodologias para análise sustentável de projeto de produtos, aplicadas em diferentes componentes.

\section{Referências}

ABNT (Associação Brasileira de Normas Técnicas). Resíduos Sólidos - Classificação - NBR 10.004. Rio de Janeiro: ABNT, 1987.

AGUIAR, Jéssica.; BOND, Danielle.; SILVA, José O.; BECKER, Daniele.; SCALICE, Regis. Proposta de ferramenta para diagnóstico da reciclabilidade de um. Em: XXIV Encontro Nacional de Engenharia de Produção, 2014, Curitiba. Anais do XXIV Encontro Nacional de Engenharia de Produção, 2014.

CHUN, Yoon-Young; LEE, Kun-Mo; LEE, Jong Seok; LEE, Joo Young; LEE, Min Hyeok; MISHIMA, Nozomu; TAHARA, Kyiotaka. Identifying key components of products based on consumer-and produceroriented ecodesign indices considering environmental impacts, costs, and utility value. Journal of Cleaner Production, v. 198, p. 1031-1043, 2018.

DHOUIB, Diala; ELLOUMI, Sonda. A new multi-criteria approach dealing with dependent and heterogeneous criteria for end-of-life product strategy. Applied Mathematics and Computation, v. 218, n. 5, p. 1668-1681, 2011.

FIKSEL, Joseph R. Design for environment. New York: Mc Graw Hill, 1996.

GIANNETTI, Biagio F.; ALMEIDA, C. M. V. B. Ecologia industrial. Conceitos, ferramentas e aplicações. São Paulo: Edgard Blucher, 2006. 
GIUDICE, Fabio; KASSEM, Mohamad. End-of-life impact reduction through analysis and redistribution of disassembly depth: A case study in electronic device redesign. Computers \& Industrial Engineering, v. 57, n. 3, p. 677-690, 2009.

KROLL, Ehud; CARVER, Brad S. Disassembly analysis through time estimation and other metrics. Robotics and Computer-Integrated Manufacturing, v. 15, n. 3, p. 191-200, 1999.

KUO, Tsai C. Enhancing disassembly and recycling planning using life-cycle analysis. Robotics and Computer-Integrated Manufacturing, v. 22, n. 5-6, p. 420-428, 2006.

KUO, Tsai Chi. Combination of case-based reasoning and analytical hierarchy process for providing intelligent decision support for product recycling strategies. Expert Systems with Applications, v. 37, n. 8, p. 5558-5563, 2010 .

MOSTAFA, Mohamed K.; PETERS, Robert W. Applying the three R's: Reduce, reuse, and recycle in the chemical industry. Journal of the Air \& Waste Management Association, v. 67, n. 3, p. 322-329, 2017.

OLSEN, Kai A.; SAETRE, Per; THORSTENSON, Anders. A procedure-oriented generic bill of materials. Computers \& industrial engineering, v. 32, n. 1, p. 29-45, 1997.

OLIVEIRA, Luana; SILVA, José O.; BOND, Danielle; BECKER, Daniela. Procedimento para determinação de índice de desmontabilidade de elementos de fixação, em: Congresso Brasileiro de gestão de desenvolvimento de produtos, 9., 2013.

PINHEIRO, Marco Antonio Paula; JUGEND, Daniel; DEMATTÊ FILHO, Luiz Carlos; ARMELLINI, Fabiano. Framework proposal for ecodesign integration on product portfolio management. Journal of Cleaner Production, v. 185, p. 176-186, 2018.

VEFAGO, Luiz H. Maccarini; AVELLANEDA, Jaume. Recycling concepts and the index of recyclability for building materials. Resources, conservation and recycling, v. 72, p. 127-135, 2013.

YU, Suiran; YANG, Qingyan; TAO, Jing; TIAN, Xia; Yin, Fengfu. Product modular design incorporating life cycle issues-Group Genetic Algorithm (GGA) based method. Journal of Cleaner Production, v. 19, n. 9-10, p. 1016-1032, 2011. 